2004 104: 2254-2262

Prepublished online Jun 29, 2004;

doi:10.1182/blood-2004-04-1506

\title{
Kinetics of engraftment in patients with hematologic malignancies given allogeneic hematopoietic cell transplantation after nonmyeloablative conditioning
}

Frédéric Baron, Jennifer E. Baker, Rainer Storb, Theodore A. Gooley, Brenda M. Sandmaier, Michael B. Maris, David G. Maloney, Shelly Heimfeld, Dmitrij Oparin, Eustacia Zellmer, Jerald P. Radich, F. Carl Grumet, Karl G. Blume, Thomas R. Chauncey and Marie-Térèse Little

Updated information and services can be found at:

http://bloodjournal.hematologylibrary.org/cgi/content/full/104/8/2254

Articles on similar topics may be found in the following Blood collections:

Immunobiology (3873 articles)

Neoplasia (4216 articles)

Transplantation (1402 articles)

Clinical Trials and Observations (2627 articles)

Information about reproducing this article in parts or in its entirety may be found online at:

http://bloodjournal.hematologylibrary.org/misc/rights.dtl\#repub_requests

Information about ordering reprints may be found online at:

http://bloodjournal.hematologylibrary.org/misc/rights.dt|\#reprints

Information about subscriptions and ASH membership may be found online at:

http://bloodjournal.hematologylibrary.org/subscriptions/index.dtl

Blood (print ISSN 0006-4971, online ISSN 1528-0020), is published

semimonthly by the American Society of Hematology, 1900 M St, NW, Suite 200, Washington DC 20036.

Copyright 2007 by The American Society of Hematology; all rights reserved.

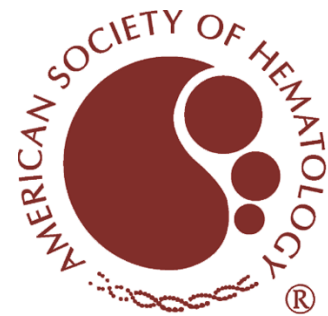




\section{Kinetics of engraftment in patients with hematologic malignancies given allogeneic hematopoietic cell transplantation after nonmyeloablative conditioning}

Frédéric Baron, Jennifer E. Baker, Rainer Storb, Theodore A. Gooley, Brenda M. Sandmaier, Michael B. Maris,

David G. Maloney, Shelly Heimfeld, Dmitrij Oparin, Eustacia Zellmer, Jerald P. Radich, F. Carl Grumet,

Karl G. Blume, Thomas R. Chauncey, and Marie-Térèse Little

We analyzed the kinetics of donor engraftment among various peripheral blood cell subpopulations and their relationship to outcomes among 120 patients with hematologic malignancies given hematopoietic cell transplantation (HCT) after nonmyeloablative conditioning consisting of 2 Gy total body irradiation (TBI) with or without added fludarabine. While patients rapidly developed high degrees of donor engraftment, most remained mixed donor/ host chimeras for up to 180 days after HCT. Patients given preceding chemotherapies and those given granulocyte colony-stimulating factor-mobilized peripheral blood mononuclear cell (G-PBMC) grafts had the highest degrees of donor chimerism. Low donor T-cell $(P=.003)$ and natural killer (NK) cell $(P=.004)$ chimerism levels on day 14 were associated with increased probabilities of graft rejection. High T-cell chimerism on day 28 was associated with an increased probability of acute graft-versus-host disease (GVHD) $(P=.02)$. Of 93 patients with measurable malignant disease at transplantation, 41 achieved complete remissions a median of 199 days after HCT; 19 of the 41 were mixed T-cell chimeras when complete remissions were achieved. Earlier establishment of donor NK-cell chimerism was associated with improved progressionfree survival $(P=.02)$. Measuring the levels of peripheral blood cell subset donor chimerisms provided useful information on HCT outcomes and might allow early therapeutic interventions to prevent graft rejection or disease progression. (Blood. 2004;104:2254-2262)

() 2004 by The American Society of Hematology

\section{Introduction}

Nonmyeloablative conditioning regimens followed by allogeneic hematopoietic cell transplantation (HCT) have been evaluated in patients with hematologic malignancies who were not considered candidates for conventional transplantation because of age or medical comorbidities. ${ }^{1-4}$ The procedure relied on the optimization of pre- and posttransplantation immunosuppression to both overcome host-versus-graft reactions and control graft-versus-host disease (GVHD). Often, nonmyeloablative regimens led to states of mixed chimerism defined as coexistence of donor- and hostderived hematopoiesis..$^{1-4} \mathrm{~A}$ variety of conditioning regimens has been evaluated with varying degrees of cytoreductive abilities. ${ }^{1,3,5-11}$ The control of malignant disease after nonmyeloablative conditioning was presumed to be dependent on engraftment of donor $\mathrm{T}$ lymphocytes and the occurrence of graft-versus-tumor (GVT) effects. ${ }^{9}$

Only a few reports to date have analyzed the engraftment kinetics of specific hematopoietic lineages after nonmyeloablative conditioning and evaluated the impact of the tempo and degree of donor chimerism on outcome. Childs et al studied chimerism evolution in 15 patients conditioned with cyclophos- phamide and fludarabine. ${ }^{9}$ The patterns of engraftment varied considerably among the patients studied, but most often, full donor chimerism was achieved earlier among $\mathrm{T}$ cells than among granulocytes, and the progression to full donor T-cell chimerism preceded GVHD and antitumor responses. ${ }^{9}$ Keil et al analyzed the impact of day-28 T-cell donor chimerism on outcome in 38 patients with various hematologic malignancies conditioned with fludarabine followed by low-dose ( $2 \mathrm{~Gy}$ ) total body irradiation (TBI). ${ }^{12}$ Generally, donor T-cell chimerism lagged behind donor myeloid chimerism. In addition, patients with less than $90 \% \mathrm{~T}$ cells of donor origin on day $28 \mathrm{had}$ significantly higher risks of graft rejection and disease relapse than those with more than $90 \%$ donor $\mathrm{T}$ cells.

Here, we describe kinetics of engraftment in 120 patients with hematologic malignancies who underwent nonablative conditioning for HCT from HLA-matched related or unrelated donors. The HCT regimen consisted of low-dose total body irradiation (TBI, 2 Gy), preceded in most patients by fludarabine, $30 \mathrm{mg} / \mathrm{m}^{2}$ per day for 3 days, and followed by immunosuppression with mycophenolate mofetil (MMF) and cyclosporine (CSP). Potential associations
From the Clinical Research Division, Fred Hutchinson Cancer Research Center, Seattle; the Department of Hematology, University of Liège, Belgium; the University of Washington School of Medicine, Seattle, WA; Stanford University, Stanford, CA; and the Veterans Affairs Medical Center, Seattle, WA.

Submitted April 20, 2004; accepted June 3, 2004. Prepublished online as Blood First Edition Paper, June 29, 2004; DOI 10.1182/blood-2004-04-1506.

Supported in part by grants CA78902, CA92058, HL36444, CA18029, CA49605, and CA15704 from the National Institutes of Health, Department of Health and Human Services (DHHS), Bethesda, MD. D.G.M. was supported by a grant from the Gabrielle Rich Leukemia Foundation. R.S. also received support from the Laura Landro Salomon Endowment Fund. F.B. is research assistant of the National Fund for Scientific Research (FNRS) Belgium and was supported in part by postdoctoral grants from the Fulbright Commission and from the Centre Anticancéreux près l'ULg. M.-T.L. also received a grant from the Muscular Dystrophy Association-USA.

An Inside Blood analysis of this article appears in the front of this issue.

Reprints: Marie-Térèse Little, Fred Hutchinson Cancer Research Center, 1100 Fairview Ave N, D1-100, PO Box 19024, Seattle, WA 98109-1024; e-mail: mlittle@fhcrc.org.

The publication costs of this article were defrayed in part by page charge payment. Therefore, and solely to indicate this fact, this article is hereby marked "advertisement" in accordance with 18 U.S.C. section 1734.

(C) 2004 by The American Society of Hematology 
between pretransplantation factors and donor chimerism values were assessed. In addition, tempo and degree of donor chimerism were correlated with outcomes including stable engraftment, survival, and progression-free survival.

\section{Patients, materials, and methods}

\section{Patients}

Data from 120 patients treated between November 1998 and December 2001 at the Fred Hutchinson Cancer Research Center, the University of Washington Medical Center, and the Veterans Affairs Medical Center (all in Seattle, WA) and at Stanford University (Stanford, CA) were included in the study. Results were analyzed as of August 1, 2002. Included in the analysis were patients with hematologic malignancies who were considered ineligible for conventional allogeneic HCT because of age and/or comorbidities, or preceding extensive therapies such as a myeloablative autologous or allogeneic HCT. ${ }^{1,3}$ Patient characteristics are summarized in Table 1. Median patient age was 54 years (range, 6-73 years), and median donor age was 47 years (range, 19-78 years). Of the 120 patients, $71 \%$ received grafts from HLAmatched related donors and 29\% from HLA-matched unrelated donors. Approximately half of the patients had indolent and another half had aggressive hematologic malignancies (defined in Table 1). Overall, 35\% of patients had failed at least one myeloablative HCT. Patients were graded into 2 categories based on the intensity of their pretransplantation chemotherapy. There were 17 patients who had not received chemotherapy or had been given agents such as chlorambucil, hydroxyurea, imatinib mesylate, or immunomodulators who were graded as " 0 ," while those who received more intensive chemotherapy $(n=103)$ were graded as " 1. " In 110 patients, the source of the hematopoietic stem cells was granulocyte colony-stimulating factor (G-CSF)-mobilized peripheral blood mononuclear cells (G-PBMCs) containing medians of $8.6 \times 10^{6} \mathrm{CD}^{2} 4^{+}$cells $/ \mathrm{kg}$ (range, $1.5-42.6 \times 10^{6} \mathrm{CD} 34^{+}$cells $/ \mathrm{kg}$ ) and $347 \times 10^{6} \mathrm{CD}^{+}$cells $/ \mathrm{kg}$ (range, $81-760 \times 10^{6} \mathrm{CD}^{+}$cells $/ \mathrm{kg}$ ). In 10 patients, all with unrelated donors, marrow was used that contained medians of $3.1 \times 10^{6} \mathrm{CD}_{4} 4^{+}$cells $/ \mathrm{kg}$ (range, 0.9-4.1 $\times 10^{6} \mathrm{CD} 34^{+}$ cells $/ \mathrm{kg}$ ) and $27 \times 10^{6} \mathrm{CD}^{+}$cells $/ \mathrm{kg}$ (range, 16-32 $\times 10^{6} \mathrm{CD}^{+}$ cells $/ \mathrm{kg}$ ). The study protocols were approved by the institutional review board of each participating institution (Fred Hutchinson Cancer Research Center, Veterans Affairs Medical Center, and Stanford University). Informed consent was obtained from all patients.

\section{Treatment and evaluation}

There were 45 recipients of HLA-matched related grafts who were conditioned with 2 Gy TBI alone either from dual cobalt 60 sources or linear accelerators, while the remaining 40 related recipients ${ }^{13}$ and all unrelated recipients were given, in addition, fludarabine, $30 \mathrm{mg} / \mathrm{m}^{2}$ per day on days $-4,-3$, and -2 , before 2 Gy TBI. Donor G-PBMCs or marrow cells were infused without processing on day 0. Postgrafting immunosuppression included MMF, $15 \mathrm{mg} / \mathrm{kg}$ orally twice a day, from the evening of day 0 until day +27 for related recipients or until day 40 at full dose and then tapered through day +96 for unrelated recipients, and CSP, $6.25 \mathrm{mg} / \mathrm{kg}$ orally twice a day, from day -3 to days 35 or 56 for related recipients or to day 100 for unrelated recipients. In the absence of GVHD, CSP was tapered through days 56, 77, or 180 for related recipients or 180 for unrelated recipients. Diagnosis and clinical grading of acute and chronic GVHD were performed according to established criteria. ${ }^{14,15}$ Decisions for treating GVHD were based on the attending physicians' assessment of the severity of GVHD. Initial treatment usually consisted of prednisolone, 1 to $2 \mathrm{mg} / \mathrm{kg}$ per day with taper started after 14 days. In addition, CSP was usually resumed at full doses. Steroid-refractory acute GVHD was treated as per available investigational protocols or other salvage regimens. Extensive chronic GVHD was usually treated with alternate-day prednisolone with or without CSP. ${ }^{16}$

Table 1. Patients $(n=120)$

\begin{tabular}{ll}
\hline \multicolumn{1}{c}{ Characteristic } & \multicolumn{1}{c}{ Value } \\
\hline Median patient age, $\mathrm{y}$ (range) & $54(6-73)$ \\
Recipient sex, no. M/no. F (\%) & $80(67) / 40(33)$ \\
Median donor age, y (range) & $47(19-78)$ \\
Donor sex, no. M/no. F (\%) & $70(58) / 50(42)$ \\
Female donor/male recipient, no. patients (\%) & $35(29)$ \\
Diagnosis, no. patients (\%) & \\
Acute myeloid leukemia & $14(12)$ \\
Acute lymphoblastic leukemia & $2(2)$ \\
Chronic myeloid leukemia & $14(12)$ \\
Chronic lymphocytic leukemia & $13(11)$ \\
Myelodysplastic syndrome & $20(17)$ \\
Multiple myeloma & $24(20)$ \\
Non-Hodgkin lymphoma & $19(16)$ \\
Hodgkin disease & $11(9)$ \\
Waldenström macroglobulinemia & $3(2)$ \\
Indolent & $61(51)$ \\
Aggressive $†$ & $59(49)$
\end{tabular}

Intensity of pretransplantation chemotherapy, $¥$ no. patients (\%)

Grade 0

$17(14)$

Grade 1

$103(86)$

Previous autograft, no. patients (\%)

CMV risk group, no. patients (\%)

Low $\left(\mathrm{R}^{-}, \mathrm{D}^{-}\right)$

Intermediate $\left(\mathrm{R}^{-}, \mathrm{D}^{+}\right)$

$26(22)$

High $\left(\mathrm{R}^{+}\right)$

$20(17)$

Donor, no. patients (\%)

HLA-identical related donor

74 (62)

HLA-Matched unrelated donor

$85(71)$

Hematopoietic stem cell source, no. patients (\%)

G-PBMC

$35(29)$

Bone marrow

$110(92)$

$10(8)$

Conditioning regimen, no. patients (\%)

$\begin{array}{ll}2 \text { Gy TBI } & 45(38) \\ 2 \text { Gy TBI + fludarabine } & 75(62)\end{array}$

Cell dose, median (range)

CD34 ${ }^{+}$cells, $\times 10^{6} / \mathrm{kg}$ recipient

$7.2(0.9-42.6)$

T cells, $\times 10^{6} / \mathrm{kg}$ recipient

$338(16-760)$

Monocytes, $\times 10^{6} / \mathrm{kg}$ recipient

$292(2-719)$

Sustained engraftment/graft rejection, no. patients (\%) $108(90) / 12(10)$

Acute GVHD, no. patients (\%)

Grade $0 \quad 45(37)$

$128(7)$

$2 \quad 49(41)$

$11(9)$

$4 \quad 7(6)$

Chronic GVHD, no. patients (\%)

No

$78(65)$

Yes $42(35)$

One-year overall survival, \%

One-year progression-free survival, \%

Measurable disease at HCT, no. patients (\%)

63

50

$93(78)$

*Defined as acute myeloid leukemia in first complete remission, acute lymphoblastic leukemia in first complete remission, myelodysplastic syndrome-refractory anemia, chronic myeloid leukemia in first chronic phase, chronic lymphoblastic leukemia, low-grade non-Hodgkin lymphoma, multiple myeloma in partial or complete remission, and Waldenström macroglobulinemia.

†All other diagnoses.

‡Patients who did not receive chemotherapy or received agents such as chlorambucil, hydroxyurea, imatinib mesylate, or immunomodulators were graded as 0 . Patients who received more intensive chemotherapy were graded as 1 .

M indicates male; F, female; R, recipient; D, donor; G-PBMC, G-CSF-mobilized peripheral blood mononuclear cells; TBI, total body irradiation; and GVHD, graftversus-host disease. 
Standard prophylaxis against Pneumocystis carinii, fungal infections, toxoplasmosis, and cytomegalovirus (CMV) infections was used. ${ }^{17,18}$ Patients with chronic GVHD requiring systemic immunosuppressive therapy continued prophylaxis against Pneumocystis carinii and pneumococcal infections.

\section{Chimerism analyses}

Percentages of donor chimerism in the different blood cell populations were assessed using polymerase chain reaction (PCR)-based analyses of polymorphic mini- or microsatellite regions (variable number tandem repeat [VNTR]). Heparinized peripheral blood samples were obtained from donors and recipients before HCT and from recipients on days 14, 28, 42, $56,84,180$, and 365 after HCT. Red blood cells (RBCs) were lysed in $8.3 \%$ ammonium chloride, centrifuged, and resuspended in phosphate-buffered saline solution (PBS) with 5\% fetal calf serum (FCS). Cells were incubated with monoclonal antibodies directed against CD3, CD4, CD8, CD14, CD33, CD45, and CD56 and directly conjugated to one of the following fluorochromes: fluorescein isothiocyanate (FITC), phycoerythrin (PE), or TRI-COLOR (TC). The antibodies were supplied by Caltag Laboratories (CT, Burlingame, CA), and Becton Dickinson (BD, San Jose, CA). After staining, cells were resuspended in PBS/FCS and stored at $4^{\circ} \mathrm{C}$ until they were analyzed and sorted.

Cell sorting. Cells were sorted by 3-color flow cytometry using a Vantage SE cytometer (BD). A large forward scatter (FSC) versus side scatter (SSC) (R1) gate was used to capture granulocytes, lymphocytes, and monocytes, and exclude debris and residual RBCs. A smaller and lower FSC versus SSC (R2) gate was used to capture lymphocytes and monocytes and exclude granulocytes. Cell types were defined as follow: T cell, $\mathrm{CD}^{+}{ }^{+} \mathrm{CD} 56^{-}$side scatter ${ }^{\text {low }} ; \mathrm{CD} 44^{+} \mathrm{T}$ cell, $\mathrm{CD} 3{ }^{+} \mathrm{CD} 4{ }^{+} \mathrm{CD} 8^{-}$side scatter ${ }^{\text {low }} \mathrm{CD}^{+} \mathrm{T}$ cell, $\mathrm{CD} 3^{+} \mathrm{CD} 4^{-} \mathrm{CD} 8^{+}$side scatter ${ }^{\text {low}}$; monocyte, $\mathrm{CD}_{14}{ }^{+} \mathrm{CD}^{-} 6^{-} \mathrm{CD}^{-}$side scatterlow; natural killer $(\mathrm{NK})$ cell, $\mathrm{CD} 56^{+} \mathrm{CD} 3{ }^{-} \mathrm{CD} 14^{-}$side scatter ${ }^{\text {low }}$; and granulocyte, $\mathrm{CD} 33^{+}$or $\mathrm{CD} 45^{+}$ side scatter ${ }^{\text {mid-hi. }}$. Cells were sorted into $1.7-\mathrm{mL}$ Eppendorf tubes containing PBS and stored on ice until the DNA was extracted, within 4 hours of sorting.

VNTR-PCR. The DNA from sorted cells was extracted using a QIAamp DNA Blood Mini Kit (Qiagen, Valencia, CA) or a Puregene Kit (Gentra Systems, Minneapolis, MN) according to the manufacturers' instructions. For PCR amplification, the following variable number tandem repeat (VNTR) and short tandem repeat (STR) loci were used: SE33, ${ }^{19}$ HUMVWA, ${ }^{20}$ DI8533, ApoB,${ }^{21}$ and DIS80. ${ }^{22}$ Informative primer sets were determined for each patient, based on patient and donor heterozygosity, allowing the use of only one primer set in subsequent PCR reactions for each donor/recipient pair. All reactions were completed in $50-\mu \mathrm{L}$ volume containing approximately $250 \mathrm{ng}$ DNA, $10 \mathrm{pmol}$ of both forward and reverse primers, 2.5 units of thermostable Thermus aquaticus DNA polymerase (Perkin Elmer, Norwalk, CT), and standard PCR reagents. The forward primer was labeled with $\gamma^{32} \mathrm{P}$ adenosine triphosphate. Cycle conditions were as follows: $95^{\circ} \mathrm{C}$ for 12 minutes followed by 30 cycles of $95^{\circ} \mathrm{C}$ for 1 minute, $56^{\circ} \mathrm{C}$ for 45 seconds $\left(60^{\circ} \mathrm{C}\right.$ for SE33), and $72^{\circ} \mathrm{C}$ for 1 minute, and a final step consisting of 10 minutes at $72^{\circ} \mathrm{C}$. Separation and detection of amplified PCR products were done by electrophoresis migration for 1 to 3 hours at $90 \mathrm{~W}(2400 \mathrm{~V})$ on a polyacrylamide gel. Mixed hematopoietic chimerism was quantified by estimating the proportion of donor-specific DNA among host DNA using the storage phosphor imaging technique (Molecular Dynamics, Sunnyvale, CA) ${ }^{23}$ as previously described. The events (reading from PhosphorImage analysis) from a donor-specific band (D) and a host-specific band $(\mathrm{H})$ were added together as total events $(\mathrm{T}=\mathrm{D}+\mathrm{H})$. The percentage of donor origin DNA was calculated as $\mathrm{D} \%=(\mathrm{D}) /(\mathrm{T}) \times 100 \%$. Mixed chimerism was defined as between $1 \%$ and $95 \%$ peripheral blood donor T lymphocytes. Depending on fragment length and efficiency of amplification, the sensitivity of the assay was between $0.1 \%$ and $5 \% .^{24-26}$

Absolute cell counts. The percentages of each cell population in a given peripheral blood sample were quantified using WinList software (Verity Software, Topsham, ME). Gates were created as defined by the sorting parameters. Once the percentages of the cell populations were determined for each subset of interest, the percentages were multiplied by the total white blood cell counts drawn on the same day as the sorted sample to determine each subpopulation's absolute cell count. Absolute donor or recipient counts were calculated by multiplying the subpopulation's absolute count by the percentages of donor or host chimerism in that subpopulation.

\section{Statistical analyses}

The impact of percent donor chimerism on rejection and acute GVHD was assessed using logistic regression, and the effects on overall and progressionfree survival were assessed using Cox regression. Chimerism was modeled in some cases as a time-dependent covariate (within the first 100 days following HCT for overall and progression-free survival), and in other cases the effect of chimerism values at a specified point in time on outcome (rejection and GVHD) was examined. The Pearson correlation coefficients were estimated to examine the correlations between donor cell subsets. The association of various factors with percent donor chimerism was evaluated with generalized estimating equations (GEEs), using chimerism values measured at days $14,28,42,56$, and 84 . $P$ values from regression models were derived from the Wald test, and no adjustments were made for multiple comparisons.

\section{Results}

\section{Donor engraftment and graft rejection}

Figure 1 summarizes the changes in peripheral blood cell changes to day +84 after HCT. Hemoglobin, neutrophil, and platelet nadirs occurred on days 32,12 , and 10 , respectively, and were $88 \mathrm{~g} / \mathrm{L}$ (range, $54-106 \mathrm{~g} / \mathrm{L}$ ), $0.33 \times 10^{9} / \mathrm{L}$ (range, 0 to $1.80 \times 10^{9} / \mathrm{L}$ ), and $45 \times 10^{9} / \mathrm{L}$ (range, 4-209 $\times 10^{9} / \mathrm{L}$ ), respectively. All patients had initial engraftment as determined by detection of $5 \%$ or more donor chimerism in at least one of the peripheral blood subpopulations. There were 12 patients who rejected their grafts 23 to 560 days (median, 52 days) after HCT. Of 45 related recipients, 5 (11\%) conditioned with 2 Gy TBI alone rejected their grafts, compared

A

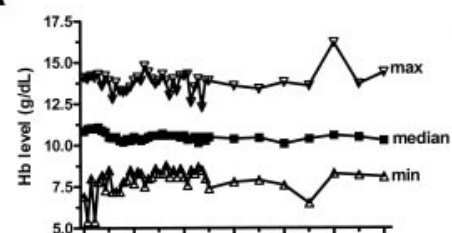

B

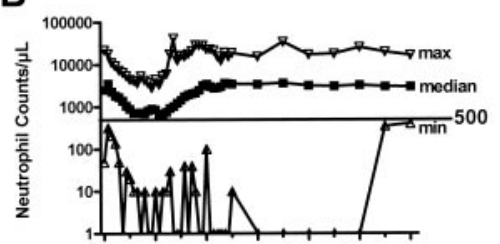

C

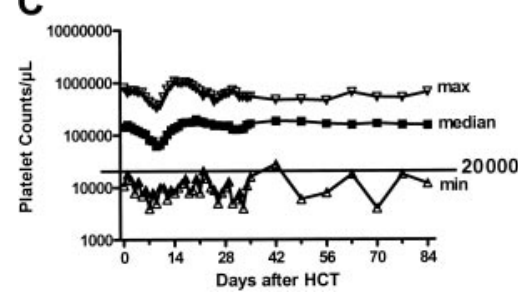

Figure 1. Hematologic changes after HCT with nonmyeloablative conditioning Peripheral blood hemoglobin, neutrophil, and platelet changes. Graphs show the medians (black squares) and ranges (open triangles) of hemoglobin $(\mathrm{Hb})$ levels, neutrophil counts, and platelet counts from days 0 through 84 
with none of 40 patients conditioned with 2 Gy TBI and added fludarabine. Of 10 unrelated marrow recipients, 4 experienced graft rejection, compared with 3 of 25 G-PBMC recipients. Of the 12 patients who rejected their transplants, 11 had autologous reconstitution. One patient had prolonged marrow aplasia along with disease relapse and died from fungal infection.

\section{Kinetics of engraftment}

Donor chimerism. The kinetics of donor cell engraftment were rapid for most patients with sustained grafts (Figure 2A). On day 14 after HCT, the highest donor contribution was seen among NK cells with a median of $79 \%$ (range, $4 \%-95 \%$ ). Donor T cells were second highest with comparable contributions from $\mathrm{CD}^{+}$(median, $69.4 \%$ [range, 28\%-94\%]) and CD4 ${ }^{+}$T-cell subsets (median, $69.1 \%$ [range, 39\%-92\%]). On day 14, the median donor monocyte chimerism was $56 \%$ (range, $2 \%-98 \%$ ), and the median donor granulocyte chimerism was $12 \%$ (range, 1\%-98\%). The donor content among granulocytes increased rapidly to a median of $90 \%$ (range, $9 \%-100 \%$ ) on day 28 , consistent with granulocyte production from engrafted donor progenitor cells and gradual elimination of host cell production. Subsequent subset analyses revealed progressive increases in donor cell contents among all cell lineages (Figure 2A). Most patients remained mixed chimeras for at least

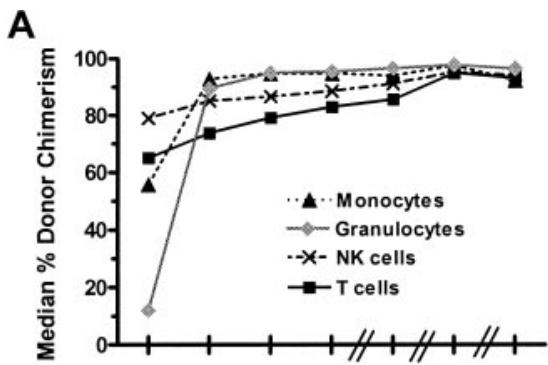

B

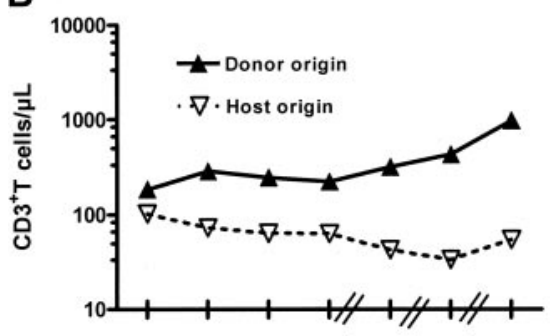

C

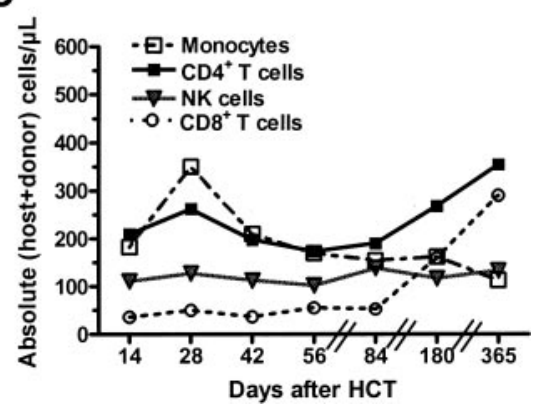

Figure 2. Kinetics of engraftment after HCT with nonmyeloablative conditioning. (A) Median percentages of donor chimerism levels among peripheral blood cell subsets in patients with sustained engraftment $(n=108)$. (B) Evolution of T cells $/ \mu \mathrm{L}$ of host and donor origin in patients with sustained engraftment. (C) Evolution of absolute (donor + recipient) CD4 ${ }^{+}$T-cell, $C D 8^{+}$T-cell, and NK-cell counts $/ \mu \mathrm{L}$.
180 days after transplantation with more than $60 \%$ donor chimerism in each subpopulation.

Correlations among donor cell subsets. Overall, donor T-cell $\left(\mathrm{CD}^{+}\right)$chimerism values on days 14 and 28 after HCT correlated closely with both donor $\mathrm{CD} 4^{+} \mathrm{T}$-cell $(\mathrm{R}=0.94)$ and $\mathrm{CD}^{+} \mathrm{T}$-cell $(\mathrm{R}=0.90)$ chimerism values on both days. Correlations between donor T-cell content and those of granulocytes $(\mathrm{R}=0.37)$, NK cells $(\mathrm{R}=0.66)$, and monocytes $(\mathrm{R}=0.56)$ were weaker.

Absolute donor cell counts. Figure $2 \mathrm{~B}-\mathrm{C}$ shows the results of enumeration of peripheral blood cell subsets. $\mathrm{CD}^{+} \mathrm{T}$ cells of donor origin increased from a median of 185 cells/ $\mu \mathrm{L}$ at day 14 to a median of 980 cells $/ \mu \mathrm{L}$ (range, $40-2140$ cells $/ \mu \mathrm{L}$ ) at one year after HCT. Median counts of T cells of recipient origin remained stable around 50 cells/ $\mu \mathrm{L}$ from day 28 to day 365 after transplantation (Figure 2B). Without exception, patients had higher absolute counts of total $\mathrm{CD}^{+} \mathrm{T}$ cells than $\mathrm{CD}^{+} \mathrm{T}$ cells immediately after HCT. Median absolute counts of CD4 ${ }^{+} \mathrm{T}$ cells remained around 200 cells $/ \mu \mathrm{L}$ for the first 3 months after HCT and then progressively increased to a median of 355 cells $/ \mu \mathrm{L}$ one year after HCT (Figure 2C). Median absolute counts of $\mathrm{CD}^{+} \mathrm{T}$ cells remained around 50 cells $/ \mu \mathrm{L}$ for the first 3 months after HCT and then increased to a median of 290 cells $/ \mu \mathrm{L}$ at one year (Figure 2C). Median counts of NK cells remained around 120 cells $/ \mu \mathrm{L}$ throughout the first year after HCT (Figure 2C). Median counts of monocytes peaked on day 28 at 350 cells $/ \mu \mathrm{L}$ and then stabilized between 110 and 170 cells/ $\mu \mathrm{L}$ (Figure $2 \mathrm{C}$ ). The median numbers of granulocytes of host origin on days 0 , 14, and 28 were 2200 per $\mu \mathrm{L}$ (range, 5-15 440 per $\mu \mathrm{L}$ ), 720 per $\mu \mathrm{L}$ (range, 1-6183 per $\mu \mathrm{L}$ ), and 300 per $\mu \mathrm{L}$ (range, 0-27 010 per $\mu L)$, respectively, suggesting that the regimen was slightly myelosuppressive. The median numbers of granulocytes of donor origin on days 14 and 28 were 110 per $\mu \mathrm{L}$ (range, 8-10 335 per $\mu \mathrm{L}$ ) and 2850 per $\mu \mathrm{L}$ (range, $80-24580$ per $\mu \mathrm{L}$ ), respectively.

\section{Associations between transplant variables and chimerism}

Hematologic disease category. The kinetics of T-cell engraftment appeared to vary depending on the underlying malignant disease (Figure 3A). Patients with lymphoid malignancies or AML tended to display higher degrees of donor T-cell chimerism than those with myelodysplastic syndrome (MDS) or chronic myelogenous leukemia $(P=.03)$.

Intensity of prior therapy and use of prior autografts. Patients who had received intensive chemotherapy before HCT had higher donor T-cell (Figure 3B), granulocyte, and monocyte chimerism levels ( $P=.002, .002$, and .01 , respectively), compared with those who did not. There was also a trend toward higher donor NK-cell chimerism $(P=.10)$. Patients who had prior autografts also had higher chimerism levels for each of the T-cell, granulocyte, monocyte, and NK-cell subpopulations $(P<.0001, P=.02$, $P=.02$, and $P=.09$, respectively).

Stem cell source and graft composition. Patients receiving G-PBMCs as stem cell source had higher percentages of donor T-cell chimerism than patients who received marrow $(P=.002)$. There were no statistically significant differences for donor granulocyte and monocyte chimerisms $(P=0.68$ and 0.37 , respectively) but a trend toward higher NK-cell chimerism $(P=.06)$ with G-PBMCs. Examining the impact of the graft composition on donor chimerism revealed that as the total T-cell, total CD4 ${ }^{+} \mathrm{T}$-cell, total $\mathrm{CD}^{+} \mathrm{T}$-cell, total monocyte, and total NK-cell contents increased, so did T-cell donor chimerism (Table 2). Except for a 

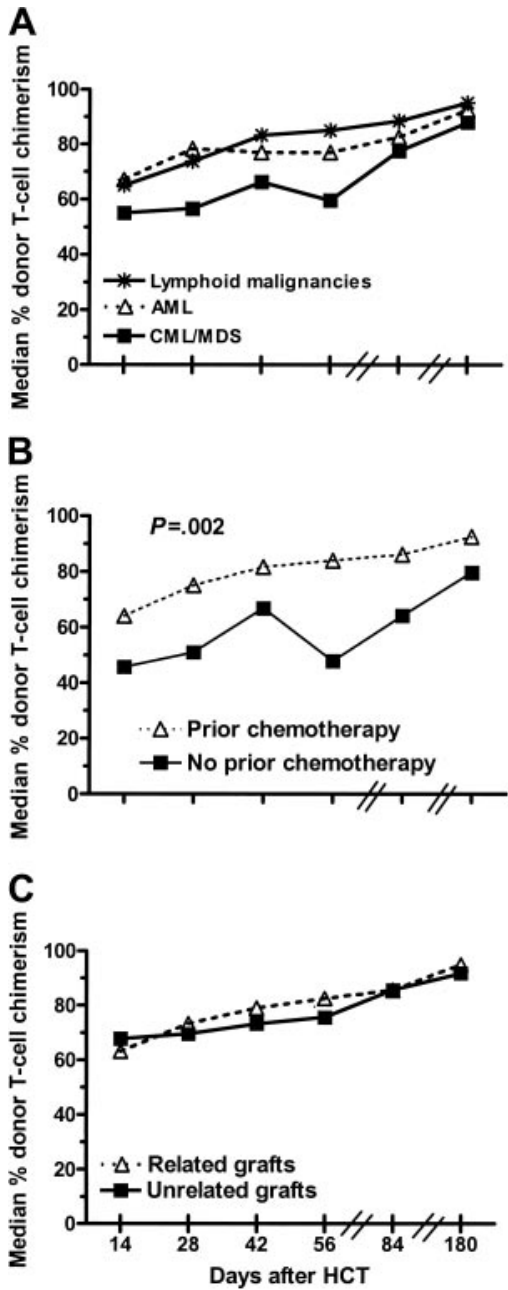

Figure 3. Associations between transplant variables and chimerism. (A) Kinetics of T-cell engraftment according to underlying diseases. (B) Kinetics of T-cell engraftment according to chemotherapy history. There were 17 patients who did no receive chemotherapy or received agents such as chlorambucil, hydroxyurea, imatinib mesylate, or immunomodulators who were termed "no prior chemotherapy, while those who received more intensive chemotherapy $(n=103)$ were termed "prior chemotherapy." (C) Comparison of kinetics of T-cell engraftment in recipients of HLA-matched related or unrelated G-PBMCs.

correlation between $\mathrm{CD} 34^{+}$cell contents and monocyte chimerism levels, no other strong correlations were seen.

Type of donor. Recipients of related grafts had statistically significantly higher donor T-cell chimerisms $(P=.01)$ and trends for higher donor granulocyte $(P=.11)$, monocyte $(P=.21)$, and NK-cell $(P=.17)$ chimerisms. When data from marrow recipients

Table 2. Correlations between graft composition and donor chimerism levels during the first 100 days after HCT

\begin{tabular}{llccc}
\hline \multirow{2}{*}{$\begin{array}{c}\text { Composition of } \\
\text { the graft }\end{array}$} & \multicolumn{2}{c}{ \% Donor chimerism as outcome* } & \\
\cline { 2 - 4 } & T cells & Granulocytes & Monocytes & NK cells \\
\hline CD34+ cells & 0.71 & 0.31 & 0.002 & 0.36 \\
T cells & 0.003 & 0.41 & 0.17 & 0.20 \\
CD4 ${ }^{+}$T cell & 0.004 & 0.37 & 0.35 & 0.31 \\
CD8 ${ }^{+}$T cell & 0.003 & 0.5 & 0.14 & 0.11 \\
Monocytes & 0.0002 & 0.09 & 0.04 & 0.05 \\
NK cells & 0.03 & 0.18 & 0.18 & 0.32 \\
\hline
\end{tabular}

${ }^{*} P$ values obtained from generalized estimated equations (GEE), using chimerism values measured at days $14,28,42,56$, and 84 after HCT. All correlations were positive.

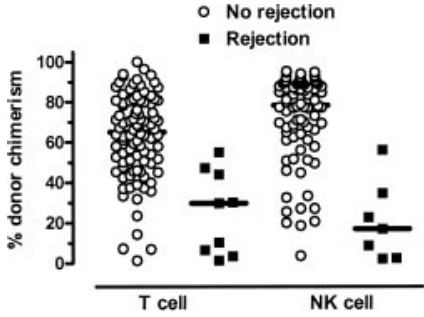

Figure 4. Day-14 donor T-cell and NK-cell chimerism levels in patients with or without subsequent graft rejection. Horizontal lines represent the median.

were excluded from analysis, patterns of engraftment were similar among patients who received HLA-matched related compared with unrelated G-PBMCs (Figure 3C).

Age. There was no statistically significant impact of patient or donor age on donor chimerism in any of the cell subsets evaluated (data not shown).

Multivariable analysis of chimerism. In multivariable analysis, the numbers of pretransplantation $\mathrm{CD}^{+} 4^{+}$cells $(P=.003$, modeled as a continuous linear variable, increased $\mathrm{CD} 34^{+}$associated with increasing chimerism) and intensive chemotherapy before HCT $(P=.04$, average increase of $15 \%$ chimerism compared with patients who did not receive intensive chemotherapy) were each associated with monocyte chimerism levels.

The number of monocytes in the graft $(P=.004$, modeled as a continuous linear variable, increased monocytes associated with increasing chimerism), intensive chemotherapy prior to HCT $(P=.006$, average increase $19 \%$ chimerism compared with no intensive chemotherapy), and previous autografts $(P=.006$, average increase $10 \%$ chimerism compared with no prior autograft) were each associated with donor T-cell chimerism levels. Recipients of unrelated grafts were more likely to reject compared with recipients of related grafts (odds ratio, 4.1; 95\% confidence interval, 1.1 to $15.5 ; P=.04)$. However, the associations between chimerism levels and rejection did not appear to depend on type of donor, although the limited number of rejections made this latter conclusion tentative at best.

\section{Association between donor chimerism levels and HCT outcomes}

Graft rejection. After initial engraftment, 12 of the 120 patients rejected their grafts. The earliest graft rejection occurred at day 23 after HCT. This permitted analyzing donor chimerism levels at day 14 in relation to subsequent rejection (Figure 4). Table 3 summarizes the results. Both, day-14 NK-cell and T-cell chimerism levels

Table 3. Association between day-14 donor chimerism levels and graft rejection

\begin{tabular}{lcccc}
\hline \multirow{2}{*}{$\begin{array}{c}\text { \% Donor } \\
\text { chimerism } \\
\text { on day } \mathbf{1 4}\end{array}$} & \multicolumn{3}{c}{ No. of patients with rejection/no. patients at risk* $(\%)$} \\
\cline { 2 - 5 } & T cells & NK cells & Monocytes & Granulocytes \\
\hline 0 to 25 & $4 / 9(44)$ & $5 / 9(56)$ & $5 / 18(28)$ & $6 / 66(9)$ \\
26 to 50 & $4 / 23(17)$ & $1 / 9(11)$ & $0 / 21$ & $2 / 15(13)$ \\
51 to 75 & $1 / 40(2.5)$ & $1 / 19(5)$ & $1 / 28(4)$ & $0 / 4(0)$ \\
76 to 90 & $0 / 22(0)$ & $0 / 35(0)$ & $0 / 15(0)$ & $0 / 6(0)$ \\
91 to 100 & $0 / 6(0)$ & $0 / 14(0)$ & $0 / 10(0)$ & $0 / 5(0)$ \\
\hline
\end{tabular}

$P$ values were obtained from trend test in a logistic regression model after adjusting for presence of unrelated donor: T cells, $P=.003$; NK cells, $P=.004$; monocytes, $P=.02$; and granulocytes, $P=.22$.

Day-14 T-cell, NK-cell, monocyte, and granulocyte chimerism data were available for $100,86,92$, and 96 patients, respectively. 
From www.bloodjournal.org by on July 9, 2009. For personal use only.

Table 4. Association between donor $\mathrm{CD}^{+}{ }^{+}$T-cell chimerism at day 28 and subsequent acute GVHD

\begin{tabular}{lcr}
\hline & $\begin{array}{c}\text { No. of patients with grades } 2 \text { to } \mathbf{4} \text { acute } \\
\text { GVHD/no. patients at risk* (\%) }\end{array}$ \\
\cline { 2 - 3 } T-cell chimerism, \% & Day $\mathbf{1 4}$ & \multicolumn{1}{c}{ Day 28 } \\
\hline 0 to 50 & $11 / 30(37)$ & $4 / 15(27)$ \\
51 to 75 & $21 / 39(54)$ & $9 / 27(33)$ \\
75 to 90 & $17 / 21(81)$ & $10 / 24(42)$ \\
91 to 100 & $2 / 6(33)$ & $6 / 8(75)$
\end{tabular}

$P$ values obtained from trend test in a logistic regression model that adjusted for presence of an unrelated donor were as follows: day $14, P=.06$, and day 28 , $P=.02$.

*Day-28 T-cell chimerism data were available for 74 of 84 patients alive without GVHD on day 28

below 50\% were associated with significantly increased risks of graft rejection after adjusting for donor type (related versus unrelated). By comparison, associations between rejection and day-14 donor granulocyte and monocyte chimerism levels were weaker. Among the 5 patients with subsequent graft rejection who had more than $20 \%$ T-cell chimerism level on day 14, 3 had increased $(>5 \%), 1$ stable, and 1 decreased $(>5 \%)$ T-cell chimerism level at the next time point. Among the 3 patients with subsequent graft rejection who had more than $20 \%$ NK-cell chimerism level on day 14,1 had increased $(>5 \%), 1$ stable, and 1 decreased $(>5 \%)$ NK-cell chimerism level at the next time point.

$\boldsymbol{G V H D}$. There were 23 patients who developed grades II to IV acute GVHD before day 28, and their data were not included in this analysis. Another 84 patients were alive without grades II to IV acute GVHD by day 28 . Table 4 analyzes the percentages of donor T-cell chimerism on day 28 in relation to the subsequent development of acute GVHD among the 84 patients. With increasing levels of donor T-cell chimerism, the probability of developing graded II to IV acute GVHD increased. This correlation was statistically significant $(P=.02)$, even after adjusting for donor type (related versus unrelated). Similar qualitative conclusions were reached using day-14 chimerism levels as opposed to day-28 levels. Of interest, most patients with grade II or grades III to IV acute GVHD remained mixed donor/host chimeras for the first 6 months after HCT (Figure 5A).

Kinetics of malignant disease responses. There were 93 patients who had measurable malignant disease before, and of these, $41(44 \%)$ achieved complete remissions after HCT. This included 5 of 14 patients with chronic myeloid leukemia, 8 of 15 patients with myelodysplastic syndrome, and 28 of 64 patients with B-cell malignancies. Sustained antitumor responses occurred almost exclusively in patients with sustained engraftment. The
A

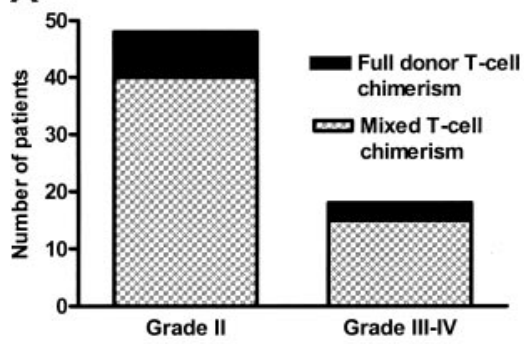

B

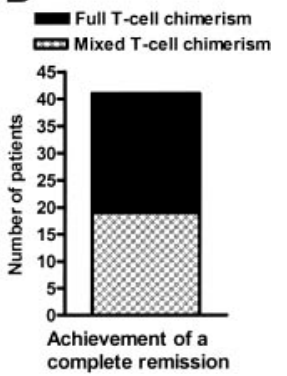

Figure 5. Distribution of T-cell chimerism. (A) At onset of grades II to IV acute GVHD. (B) At the time of achievement of complete remissions in patients with measurable disease at HCT. Full donor T-cell chimerism was defined by donor contribution of $95 \%$ or more.
Table 5. Association between donor T-cell chimerism status at day 28 and subsequent complete remissions of the underlying malignancies

\begin{tabular}{lc}
\hline T-cell chimerism, \% & $\begin{array}{c}\text { No. of patients with complete } \\
\text { remissions/no. patients at risk (\%) }\end{array}$ \\
\hline $0-50$ & $3 / 15(20)$ \\
$51-75$ & $13 / 26(50)$ \\
$75-90$ & $9 / 20(45)$ \\
$90-100$ & $5 / 11(45)$ \\
\hline
\end{tabular}

Analysis restricted to patients alive and without complete responses by day 28 .

${ }^{*} P$ value $(P=.16)$ obtained from trend test in a Cox regression model adjusting for presence of indolent disease, use of fludarabine, and use of an unrelated donor.

median time to achieve complete remissions was 199 days (range, 28-963 days). At the time of disease response, 19 of the 41 patients showed mixed donor/host T-cell chimerism (median, $83 \%$ [range, 24\%-93\%]), and 22 had complete donor T-cell chimerism (Figure $5 B)$. The levels of neither early T-cell nor early NK-cell donor chimerism (measured at day 28) were statistically significantly associated with the accomplishment of complete remissions, although there was a suggestion that donor T-cell chimerism below $50 \%$ was associated with a decreased chance of achieving complete remissions compared with T-cell chimerism above 50\% (Table 5). Further, 59 of the 93 patients with measurable disease before HCT developed acute GVHD and 34 patients did not. Of the 59 patients with acute GVHD, 26 (44\%) achieved complete remissions compared with 15 (44\%) of the 34 patients without acute GVHD. Treating the occurrence of grades II to IV acute GVHD as a time-dependent covariate, there was no suggestion of an association between acute grades II to IV GVHD and the probability of achieving complete remissions $(P=.92)$.

Figure 6 illustrates the kinetics of disease response and donor T-cell chimerism in a patient with CML in first chronic phase who had received an HLA-matched related transplant. Levels of donor T-cell chimerisms were $46 \%, 77 \%, 66 \%, 100 \%$, and $100 \%$ on days $14,42,120,270$, and 365, respectively. The patient achieved a complete cytogenetic response by day 56 and a complete molecular remission by day 180 .

A
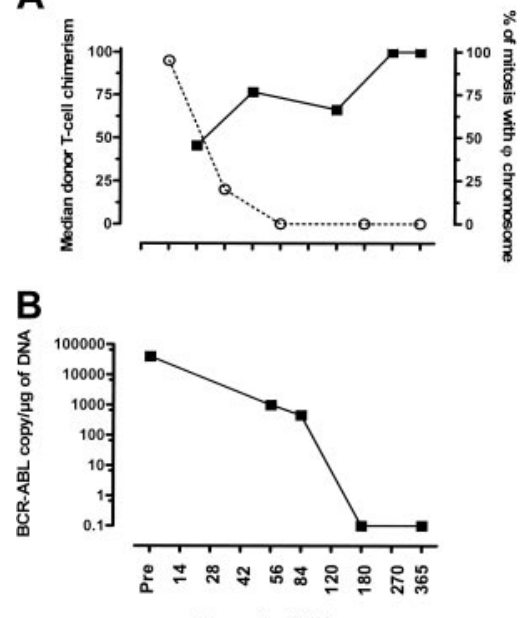

Days after HCT

Figure 6. CML patient with complete cytogenetic remission before achieving full donor T-cell chimerism. (A) Evolution of T-cell chimerism (black squares, solid line) and percentages of mitoses with Philadelphia chromosome determined by conventional cytogenetics (open circle, broken line). (B) Achievement of molecular remission. 
Table 6. Association between donor chimerism levels in various peripheral blood cell subpopulations and overall mortality and death or relapse/progression

\begin{tabular}{lcccccccc}
\hline & \multicolumn{3}{c}{ Mortality } & & \multicolumn{2}{c}{$\begin{array}{c}\text { Death or } \\
\text { relapse/progression }\end{array}$} \\
\cline { 2 - 3 } Subpopulation & $\begin{array}{c}\text { Hazard } \\
\text { ratio* }\end{array}$ & $\mathbf{9 5 \%} \mathbf{C l}$ & $\boldsymbol{P}$ & & $\begin{array}{c}\text { Hazard } \\
\text { ratio* }\end{array}$ & $\mathbf{9 5 \%} \mathbf{C l}$ & $\boldsymbol{P}$ \\
\hline Granulocytes & 0.83 & $0.70-1.00$ & .06 & & 0.89 & $0.72-1.10$ & .28 \\
T cells & 0.94 & $0.77-1.15$ & .59 & & 0.89 & $0.72-1.06$ & .19 \\
Monocytes & 0.82 & $0.68-0.98$ & .04 & & 0.89 & $0.72-1.08$ & .21 \\
NK cells & 0.83 & $0.68-1.02$ & .09 & & 0.79 & $0.64-0.96$ & .02
\end{tabular}

*Percent donor chimerism modeled as a continuous linear variable. Hazard ratio presented in terms of an increase in percent donor chimerism of $20 \%$.

Overall survival and progression-free survival. The 2-year probabilities of overall survival for patients with acute leukemia, myelodysplastic syndrome, chronic myeloid leukemia, and B-cell malignancies were $40 \%, 40 \%, 46 \%$, and $60 \%$, respectively. When donor chimerism values (for the various subpopulations) were treated as time-dependent covariates, there were suggestions that faster establishment of complete donor granulocyte, monocyte, and NK-cell chimerisms was associated with better survival (Table 6). More rapid establishment of donor NK-cell chimerism was associated with statistically significantly improved progression-free survival

\section{Discussion}

Allogeneic HCT after nonmyeloablative conditioning of 2 Gy $\mathrm{TBI} \pm$ fludarabine and with postgrafting immunosuppression with MMF and CSP has been used to treat patients with hematologic malignancies who were not eligible for conventional HCT. ${ }^{1-4}$ Here, we analyzed engraftment kinetics among peripheral blood cell subpopulations and their relationships to postgrafting outcomes in 120 patients who were conditioned with that regimen. The following observations were made.

While patients rapidly developed high degrees of donor engraftment, the majority remained mixed donor/host chimeras during the first 6 months after HCT. Overall, donor T-cell chimerism values correlated closely with both donor $\mathrm{CD}^{+}{ }^{+} \mathrm{T}$-cell and $\mathrm{CD} 8^{+} \mathrm{T}$-cell subset chimerism values, but correlation between donor T-cell content and those of granulocyte, NK cells, and monocytes were weaker, emphasizing the importance of "lineage"-specific analyses for accurate assessment of mixed chimerism.

Donor T-cell reconstitution was slow, with normalization of absolute $\mathrm{CD} 8^{+} \mathrm{T}$-cell counts approximately 6 months after HCT, while $\mathrm{CD}^{+}{ }^{+} \mathrm{T}$-cell counts remained below 400 cells $/ \mu \mathrm{L}$ for at least one year, findings that were consistent with those reported previously. ${ }^{27,28}$ Significant numbers of $\mathrm{T}$ cells of host origin survived the nonmyeloablative regimen and continued to be present at relatively constant low (approximately 50 cells $/ \mu \mathrm{L}$ ) levels throughout the observation period. Persistence of host $\mathrm{T}$ cells might explain why CMV-seropositive nonablative recipients had significantly higher numbers of CMV-specific helper $\mathrm{T}$ cells and lower rates of CMV disease than ablative recipients during the first 100 days after HCT. ${ }^{28,29}$

Several factors were identified that correlated with donor chimerism levels. Prior chemotherapy exposure was associated with higher levels of donor $\mathrm{T}$ cells, granulocytes, and monocytes, also consistent with previous observations. Valcarcel et al found that more than 2 courses of chemotherapy before transplan- tation were associated with complete day-30 donor chimerism in unfractionated peripheral blood cells among 68 patients conditioned with fludarabine/melphalan or fludarabine/busulfan. ${ }^{30}$ Similarly, Carvallo et al showed that prior chemotherapy exposure led to rapid donor myeloid and T-cell engraftment in patients with solid tumors conditioned with fludarabine and cyclophosphamide. ${ }^{31}$ Prior chemotherapy likely facilitated engraftment by decreasing the recipients' immune competence, thereby weakening host-versus-graft reactions. We also found significant correlations between graft contents and levels of donor chimerisms. Higher T-cell (including $\mathrm{CD}^{+}$and $\mathrm{CD} 8^{+}$ T-cell subsets), monocyte, and NK-cell contents in the grafts were associated with higher T-cell donor chimerisms, while higher $\mathrm{CD}_{3} 4^{+}$cell and monocyte contents resulted in higher donor monocyte chimerisms. As T-cell and monocyte graft contents were highly correlated, it was difficult to determine which one was responsible for the observed increased T-cell engraftment. However, previous observations in the canine model showing that addition of G-PBMCs but not of CD3depleted G-PBMCs to marrow enhanced allogeneic engraftment drew attention toward T cells. ${ }^{32}$ Carvallo et al also analyzed the impact of graft composition on donor chimerism levels in their patients. ${ }^{31}$ They found that $\mathrm{CD} 34^{+}$cell doses correlated with the degree of donor myeloid chimerism but failed to establish correlations between graft composition and donor T-cell chimerism levels. Current findings suggested that adjustments of the numbers of T cells and monocytes in the grafts might be possible to better control rejection and/or GVHD.

Day-14 donor NK or T-cell chimerism levels below $50 \%$ were significantly associated with higher risk of graft rejection. An increased incidence of graft rejection in patients with mixed donor/host chimerism was first reported in aplastic anemia patients conditioned with cyclophosphamide. ${ }^{33}$ Few studies have analyzed the effect of lineage-specific chimerisms on graft rejection after nonmyeloablative or reduced-intensity regimens. We previously reported that the level of day-28 donor T-cell but not granulocyte chimerism was correlated with graft rejection after nonablative regimen. ${ }^{1,3}$ Also, Matthes-Martin et al showed that day-28 T-cell and NK-cell chimerisms were correlated with late graft rejection in pediatric patients conditioned with a reduced-intensity regimen. ${ }^{34}$ Bornhauser et al suggested that patients with NK-cell donor chimerism levels below $75 \%$ on days 10 to 30 after HCT were more likely to reject their grafts than those with more than $75 \%$ after conditioning with fludarabine/busulfan. ${ }^{11}$ The current demonstration that patients at high risk of graft rejection could be identified as early as day 14 after HCT might allow early interventions aimed at reversing graft rejection.

A significant association between acute GVHD and higher levels of donor T-cell chimerism was seen. However, most patients were mixed T-cell chimeras at the onset of grades II to IV acute GVHD, demonstrating that mixed chimerism did not provide absolute protection from GVHD. These results contrast with those reported by Childs et al, who found that $100 \%$ donor T-cell engraftment always preceded GVHD. ${ }^{9}$ Perhaps differences in the conditioning regimens and postgrafting immunosuppression used could explain the different observations. Childs et al used fludarabine/cyclophosphamide for conditioning and administered CSP alone as immunosuppressive therapy.

Sustained antitumor responses were seen among $44 \%$ of patients with measurable disease, and these responses occurred nearly exclusively in patients with sustained engraftment. The median time to achieve complete remissions was 199 days, and 
almost half of the patients were mixed T-cell chimeras at the time responses were complete. This also contrasted with data reported by Childs et al, who noted antitumor responses only after $100 \%$ donor T-cell chimerism had occurred. ${ }^{9}$

Current results suggested that faster establishment of donor granulocyte, NK-cell, and monocyte chimerisms was associated with improved survival. Further, earlier full-donor NK-cell chimerism correlated with better progression-free survival. However, these associations were relatively weak and must be confirmed in larger patient cohorts and for individual diseases. The impact of persistent stable mixed chimerism on relapse and progression-free survival after myeloablative allogeneic HCT has been controversial. ${ }^{35-38}$ Petz et al observed that mixed donor/host chimerism did not convey an increased risk of relapse, ${ }^{35}$ but Huss et al reported that the presence of mixed chimerism after day 100 was associated with increased relapse risk in a subset of patients with CML. However, among the overall cohort of patients studied, those who were mixed chimeras had better disease-free survival because of less GVHD. ${ }^{38}$ Mackinnon et al reported that minimal residual disease was more common in CML patients with mixed T-cell chimerism after HCT. ${ }^{37}$ Keil et al demonstrated a significantly higher risk of relapse and significantly worse progression-free survival in patients with less than $90 \%$ donor T-cell chimerism on day 28 compared with those with $90 \%$ or more donor T-cell chimerism. ${ }^{12}$ The current study failed to show such an association between early T-cell chimerism and progression-free survival. Analyses of data from larger numbers of patients with individual diseases and treated with uniform HCT regimens might help clarify these contradictory observations.

In conclusion, monitoring the levels of donor chimerism among peripheral blood cell subpopulations after HCT with a nonmyeloablative regimen might help identify patients at risk for graft rejection, acute GVHD, and death/relapse and thereby allow early interventions with immunosuppressive drugs or donor lymphocyte infusions.

\section{Acknowledgments}

We thank Heather Hildebrant and Deborah Bassuk for data processing; the research nurses Steve Minor, Mary Hinds, and John Sedgwick; the medical nursing and clinical staffs for their dedicated care of the patients; and Bonnie Larson and Helen Crawford for help with manuscript preparation.

\section{References}

1. McSweeney PA, Niederwieser D, Shizuru JA, et al. Hematopoietic cell transplantation in older patients with hematologic malignancies: replacing high-dose cytotoxic therapy with graft-versustumor effects. Blood. 2001;97:3390-3400.

2. Niederwieser D, Maris M, Shizuru JA, et al. Lowdose total body irradiation (TBI) and fludarabine followed by hematopoietic cell transplantation (HCT) from HLA-matched or mismatched unrelated donors and postgrafting immunosuppression with cyclosporine and mycophenolate mofetil (MMF) can induce durable complete chimerism and sustained remissions in patients with hematological diseases. Blood. 2003;101:1620-1629.

3. Maris MB, Niederwieser D, Sandmaier BM, et al. HLA-matched unrelated donor hematopoietic cell transplantation after nonmyeloablative conditioning for patients with hematologic malignancies. Blood. 2003;102:2021-2030.

4. Maloney DG, Molina AJ, Sahebi F, et al. Allografting with nonmyeloablative conditioning following cytoreductive autografts for the treatment of patients with multiple myeloma. Blood. 2003;102: 3447-3454.

5. Slavin S, Nagler A, Naparstek E, et al. Nonmyeloablative stem cell transplantation and cell therapy as an alternative to conventional bone marrow transplantation with lethal cytoreduction for the treatment of malignant and nonmalignant hematologic diseases. Blood. 1998;91:756-763.

6. Giralt S, Estey E, Albitar M, et al. Engraftment of allogeneic hematopoietic progenitor cells with purine analog-containing chemotherapy: harnessing graft-versus-leukemia without myeloablative therapy. Blood. 1997;89:4531-4536.

7. Khouri IF, Keating M, Körbling M, et al. Transplant-lite: induction of graft-versus-malignancy using fludarabine-based nonablative chemotherapy and allogeneic blood progenitor-cell transplantation as treatment for lymphoid malignancies. J Clin Oncol. 1998;16:2817-2824.

8. Spitzer TR, McAfee S, Sackstein R, et al. Intentional induction of mixed chimerism and achievement of antitumor responses after nonmyeloablative conditioning therapy and HLA-matched donor bone marrow transplantation for refractory hematologic malignancies. Biol Blood Marrow Transplant. 2000;6:309-320

9. Childs R, Clave E, Contentin N, et al. Engraft- ment kinetics after nonmyeloablative allogeneic peripheral blood stem cell transplantation: full donor T-cell chimerism precedes alloimmune responses. Blood. 1999;94:3234-3241.

10. Kottaridis PD, Milligan DW, Chopra R, et al. In vivo CAMPATH-1H prevents graft-versus-host disease following nonmyeloablative stem cell transplantation. Blood. 2000;96:2419-2425.

11. Bornhauser M, Thiede C, Platzbecker $U$, et al. Dose-reduced conditioning and allogeneic hematopoietic stem cell transplantation from unrelated donors in 42 patients. Clin Cancer Res. 2001;7: 2254-2262.

12. Keil F, Prinz E, Moser K, et al. Rapid establishment of long-term culture-initiating cells of donor origin after nonmyeloablative allogeneic hematopoietic stem-cell transplantation, and significant prognostic impact of donor T-cell chimerism on stable engraftment and progression-free survival. Transplantation. 2003;76:230-236.

13. Sandmaier BM, Maloney DG, Gooley TA, et al Low dose TBI conditioning for hematopoietic stem cell transplants (HSCT) from HLA-matched related donors for patients with hematologic malignancies: influence of fludarabine or cytoreductive autografts on outcome [abstract]. Blood. 2002;100(pt 1):145a. Abstract no. 544.

14. Przepiorka D, Weisdorf D, Martin P, et al. 1994 Consensus conference on acute GVHD grading. Bone Marrow Transplant. 1995;15:825-828.

15. Lee SJ, Vogelsang G, Flowers MED. Chronic graft-versus-host disease. Biol Blood Marrow Transplant. 2003;9:215-233.

16. Koc S, Leisenring W, Flowers MED, et al. Therapy for chronic graft-versus-host disease: a randomized trial comparing cyclosporine plus prednisone versus prednisone alone. Blood. 2002;100:48-51

17. Junghanss $C$, Marr KA, Carter RA, et al. Incidence and outcome of bacterial and fungal infections following nonmyeloablative compared with myeloablative allogeneic hematopoietic stem cell transplantation: a matched control study. Biol Blood Marrow Transplant. 2002;8:512-520.

18. Fukuda T, Boeckh M, Carter RA, et al. Risks and outcomes of invasive fungal infections in recipients of allogeneic hematopoietic stem cell transplants after nonmyeloablative conditioning. Blood. 2003;102:827-833.
19. Polymeropoulos MH, Rath DS, Xiao H, Merril CR. Tetranucleotide repeat polymorphism at the human beta-actin related pseudogene $\mathrm{H}$-beta Acpsi-2 (ACTBP2). Nucleic Acids Res. 1992;20: 1432-1432.

20. Kimpton C, Walton A, Gill P. A further tetranucleotide repeat polymorphism in the VWF gene. Hum Mol Genet. 1992;1:287.

21. Boerwinkle E, Xiong WJ, Fourest E, Chan L. Rapid typing of tandemly repeated hypervariable loci by the polymerase chain reaction: application to the apolipoprotein B $3^{\prime}$ hypervariable region. Proc Natl Acad Sci U S A. 1989;86:212-216.

22. Kasai K, Nakamura $Y$, White R. Amplification of a variable number of tandem repeats (VNTR) locus (pMCT118) by the polymerase chain reaction (PCR) and its application to forensic science. J Forensic Sci. 1990;35:1196-1200.

23. Reichert WL, Stein JE, French B, Goodwin P, Varanasi U. Storage phosphor imaging technique for detection and quantitation of DNA adducts measured by the 32P-postlabeling assay. Carcinogenesis. 1992;13:1475-1479.

24. Storb R, Yu C, McSweeney P. Mixed chimerism after transplantation of allogeneic hematopoietic cells. In: Thomas ED, Blume KG, Forman SJ, eds. Hematopoietic Cell Transplantation. 2nd ed. Boston, MA: Blackwell Science; 1999:287-295.

25. Antin JH, Childs R, Filipovich AH, et al. Establishment of complete and mixed donor chimerism after allogeneic lymphohematopoietic transplantation: recommendations from a workshop at the 2001 Tandem Meetings (Review). Biol Blood Marrow Transplant. 2001;7:473-485.

26. Vignaux F, Hitte C, Priat C, Chuat JC, Andre C, Galibert F. Construction and optimization of a dog whole-genome radiation hybrid panel. Mamm Genome. 1999;10:888-894.

27. Baron F, Schaaf-Lafontaine N, Humblet-Baron S, et al. T-cell reconstitution after unmanipulated, CD8-depleted or CD34-selected nonmyeloablative peripheral blood stem-cell transplantation. Transplantation. 2003;76:1705-1713.

28. Maris M, Boeckh M, Storer B, et al. Immunologic recovery after hematopoietic cell transplantation with nonmyeloablative conditioning. Exp Hematol. 2003;31:941-952.

29. Junghanss C, Boeckh M, Carter RA, et al. Incidence and outcome of cytomegalovirus infections 
From www.bloodjournal.org by on July 9, 2009. For personal use only.

following nonmyeloablative compared with myeloablative allogeneic stem cell transplantation, a matched control study. Blood. 2002;99:1978 1985.

30. Valcarcel D, Martino R, Caballero D, et al. Chimerism analysis following allogeneic periphera blood stem cell transplantation with reduced-intensity conditioning. Bone Marrow Transplant. 2003;31:387-392.

31. Carvallo C, Geller N, Kurlander R, et al. Prior chemotherapy and allograft CD34+ dose impact donor engraftment following nonmyeloablative allogeneic stem cell transplantation in solid tumor patients. Blood. Prepublished on October 9, 2003, as DOI 10.1182/blood-200304-1170. (Now available as Blood. 2004;103: 1560-1563).

32. Zaucha JM, Zellmer E, Georges G, et al. G-CSF mobilized peripheral blood mononuclear cells added to marrow facilitates engraftment in nonmyeloablated canine recipients: CD3 cells are required. Biol Blood Marrow Transplant. 2001;7: 613-619.

33. Hill RS, Petersen FB, Storb R, et al. Mixed hematologic chimerism after allogeneic marrow transplantation for severe aplastic anemia is associated with a higher risk of graft rejection and a lessened incidence of acute graft-versus-host disease. Blood. 1986;67:811-816.

34. Matthes-Martin S, Lion T, Haas OA, et al. Lineage-specific chimaerism after stem cell transplantation in children following reduced intensity conditioning: potential predictive value of NK cell chimaerism for late graft rejection. Leukemia. 2003;17:1934-1942.

35. Petz LD, Yam P, Wallace RB, et al. Mixed hematopoietic chimerism following bone marrow trans- plantation for hematologic malignancies. Blood. 1987;70:1331-1337.

36. Schaap N, Schattenberg A, Mensink E, et al. Long-term follow-up of persisting mixed chimerism after partially T cell-depleted allogeneic stem cell transplantation. Leukemia. 2002;16:13-21.

37. Mackinnon S, Barnett L, Heller G, O'Reilly RJ. Minimal residual disease is more common in patients who have mixed T-cell chimerism after bone marrow transplantation for chronic myelogenous leukemia. Blood. 1994;83:34093416.

38. Huss R, Deeg HJ, Gooley T, et al. Effect of mixed chimerism on graft-versus-host disease, disease recurrence, and survival after HLA-identical marrow transplantation for aplastic anemia or chronic myelogenous leukemia. Bone Marrow Transplant. 1996:18:767-776. 